\title{
A Novel Fluorescence "Turn-Off" Sensor Base On A Triazole-Linked BINOL-Glucose Derivative For The Sensitive Detection of Copper Ion
}

Huizhen Wang

Jiangxi Science and Technology Normal University

Yang Liu

Jiangxi Science and Technology Normal University

Xiaoxia Sun ( $\square$ sunxiaoxia77@126.com )

Jiangxi Science and Technology Normal University

Yu Hu

Nanchang University

Research Article

Keywords: Click reaction, Fluorescent sensor, Copper ion detection, Ratiometric detection

Posted Date: August 11th, 2021

DOI: https://doi.org/10.21203/rs.3.rs-777885/v1

License: (a) (i) This work is licensed under a Creative Commons Attribution 4.0 International License.

Read Full License 


\section{Abstract}

A novel sensitive chiral fluorescent "turn-off" sensor based on 3,3'-positions modified triazole-linked BINOL-Glucose derivative has been synthesized via "click" reaction. The fluorescence emission intensity of $(S, \beta-D)-1$ was almost completely quenched along with obvious color change from yellow to green upon the coordination with a $\mathrm{Cu}(\mathrm{II})$ ion while other metal ions had no obvious change. The detection limit of the sensor $(S, \beta-D)-1$ toward copper ion was calculated to be $0.31 \mu \mathrm{mol} \mathrm{L}^{-1}$. The stoichiometry ratio of $(S, \beta-D)-1^{-} \mathrm{Cu}^{2+}$ complex was proved to be 1:1 by the analysis of NMR spectroscopic, ESI-MS data and the job's plot. HNMR spectroscopic and IR were also used to study the mechanism, demonstrated copper ion was coordinated with $(S, \beta-D)-\mathbf{1}$ by $1+1$ complex formation.

\section{Highlights}

- A new 3,3'-positions modified triazole-linked BINOL-Glucose derivative sensor was synthesized for the first time.

- Probe $(S, \beta-D)$-1 can discriminate copper ion with an obvious naked-eye colorimetric behavior and an obvious fluorescence turn-off behavior.

- The $\mathrm{Cu}^{2+}$-induced fluorescence quenching may be attributed to the intramolecular proton transfer through six-member ring transition state from phenolic hydroxyl groups to the adjacent $\mathrm{OCH}_{2}$ group in excited-state and a PET effect of the copper $1+1$ complex.

\section{Introduction}

Followed by zinc and iron, as the third most abundant essential microelement in human body, $\mathrm{Cu}^{2+}$ also plays vital roles in the human body and plant tissues during the fundamental physiological processes of

organisms $^{1-7}$. However, at higher concentration levels, copper produces toxicity and could result in a wide variety of potential health risks ${ }^{8-16}$, such as Hashimoto's disease, pelvic inflammatory disease (PID), Alzheimer's, neurodegenerative disorders, stomach cramps, Wilson's diseases, fibrocystic breast disease and prion diseases. Furthermore, the development of modern industry and agriculture has caused serious transition metals pollutions, such as $\mathrm{Cu}^{2+}$, have resulted in severe environmental pollution and destructed natural ecosystems, particularly the serious drinking water pollution. ${ }^{17-20} \mathrm{Hence}$, it is highly meaningful and still a challenging to protect human health and environment and find or design a new method to monitor and selective detect $\mathrm{Cu}^{2+}$.

A large amount of analytical methods, for example, electrochemical method, atomic absorption spectroscopy (AAS), ICP-MS and colorimetric method had been applied to detect $\mathrm{Cu}^{2+}$, in consideration of the importance of copper ion. ${ }^{3,19-23}$ But these analytical methods have not been achieved applications for online monitoring of $\mathrm{Cu}^{2+}$ feasibly and effectively owing to their expensive instruments, wellcontrolled experimental conditions, tedious time-consuming sample preparation and delayed responses. Compared to other classical techniques, fluorescent probes have attracted enormous attention because 
of theirs rapid response, real-time analysis, facile operation and high selectivity and sensitivity. ${ }^{21-24}$ The fluorescence method with innate high sensitivity has attracted increasing attention to investigate molecule-based fluorescent sensors, which could offer multiple signaling modes, for example enhancement, quenching, lifetime, anisotropy, and excimer/ exciplex formation of substrate analysis. Fluorescent sensors applied or tagged to detect anions, metal cations, neutral molecules, protons and chiral organic compounds have received detailed investigated. At present, monitoring of copper ion was focused on the design and synthesis of fluorescent probes with high sensitivity and selectivity. Over the past few years, different fluorescent sensors based on rhodamine ${ }^{25,26}$, naphthalimides ${ }^{27}$, coumarin $^{28,29}$, Bodipy ${ }^{30,31}$ and qulioline ${ }^{32}$, using the detection of $\mathrm{Cu}^{2+}$ have been reported. Most of the probes were interfered by other transition metals, especially $\mathrm{Hg}^{2+}$ in the discrimination of $\mathrm{Cu}^{2+}$ with the emission quenching intensity ${ }^{33}$. However, it still remains rather challenging to design effective specific fluorescent sensors for copper ion with high sensitivity and selectivity.

As a fluorescent chemical sensor, rapid identification of metal ions and chiral isomers with high selectivity and sensitivity are the remarkable advantage of chiral BINOL derivatives. As the versatile backbone of BINOL, it can be easily modified from space effects and electronic effects, it and its derivatives ${ }^{34-38}$ have caused considerable focus on the field of fluorescent chemical sensors ${ }^{39-49}$ and asymmetric catalysis. Chiral BINOL derivatives have the distinct characteristics: ${ }^{50-54}$ easily modified by functional groups especially tuned to the 2-, 3-, 4-, 5- and 6-positions of the chiral optical pure BINOL and commercially available with both enantioselective enantiomers, (R)- and (S)BINOL. Moreover, glucose has attracted more attention because of its good biocompatibility, variety structural modification, natural existence and without toxic during the recent years. Furthermore, the best water solubility of glucose was the most ideal advantage as composing fluorescent chemical sensors. In the past few years, 1,2,3-triazole modified sugar derivatives have attracted continuous focus on the chemistry research ${ }^{55-57}$ and sugarbased fluorescent chemical sensor ${ }^{58-65}$. We have investigated the application of a BINOL-Glucose derivative ${ }^{66}$ fluorescent sensor to discriminate $\mathrm{Ag}^{+}$companied with high enantioselectivity and sensitivity without interference of $\mathrm{Hg}^{2+}$. Based on the 3,3'-positions structural modification versatile backbone of $(S)$ BINOL and considered (S)-BINOL and two 1,2,3-triazole units as fluorophore and recognition group, respectively. Detailed investigation on the application of the Glucose modified triazole-based sensor in the molecular recognition of metal ions was processed in this study. At the same time, 3,3'-position modified triazole-linked 1,1'-bi-2-naphthol (BINOL) derivative displayed highly fluorescent quenching by the combination with $\mathrm{Cu}^{2+}$ in the presence of large amounts of competing ions as we expected.

\section{Result And Discussion}

\subsection{Synthesis}

The 3,3'-position modified BINOL-Glucose derivative $(S, \beta-D)$-1 were synthesized from the readily available (S)-2,2'-bis(methoxymethoxy)-3,3'-diformyl-1,1'-binaphthol (S-2) as shown in Scheme 1. According to the former literature, protection of 2,2'-binaphthol (BINOL) with methoxymethyl (MOM) groups obtained 
(S)-2,2'-bis(methoxymethoxy)-1,1'-binaphthol in $91 \%$ yield. $S-2$ was treated with n-BuLi and followed by the addition of N,N-Dimethylformamide to produce $S-3$ in $47 \%$ yield as a yellow solid. The dipropargyl $S-4$ derivative was synthesized by 3-bromo-1-propyne and $S-3$. The protecting groups of $S-4$ were taken off with hydrochloric acid to generate 3,3'-bis(0-Propargyloxymethyl)-BINOL $S \mathbf{5}$ as a brown oil in $85 \%$ yield with hydrochloric acid. The click reaction of 2,3,4,6-Tetra-0-acetyl-beta-D-glucopyranosyl azide and 3,3'bis(O-Propargyloxymethyl)-BINOL were processed in THF, catalyzed by copper (II) sulfate and sodium ascorbate to afford the target sensor with moderate yield. The structures of the desired product were demonstrated by IR, ${ }^{1} \mathrm{HNMR},{ }^{13} \mathrm{CNMR}$, and ESI-MS. ${ }^{1} \mathrm{H}$ NMR spectrum of $(S, \beta-D)-1$ in $\mathrm{CD}_{3} \mathrm{CN}$ exhibited a deshield proton signal at $\delta 7.06$ for the hydroxyl groups, according to a weak hydrogen-bonding interaction with the adjacent $\mathrm{OCH}_{2}$ group. The hydroxyl proton peaks of BINOL derivatives were usually appeared at $\delta<6$. The weak hydrogen-bonding interaction could also be demonstrated by a strong single absorption band at $1227 \mathrm{~cm}^{-1}$ in IR spectrum while the hydroxyl proton peaks of BINOL derivatives exhibited a weak peak at the same absorption band.

\subsection{Fluorescence response to $\mathrm{Cu}^{2+}$}

The fluorescence response of $(S, \beta-D)-1(20 \mu \mathrm{M})$ in acetonitrile solution upon irradiation with UV/vis lights were also investigated by a fluorescence spectroscopy. As shown in Fig. 1, $(S, \beta-D)$-1 displayed moderate fluorescence at $376 \mathrm{~nm}$ with the excitation light at $287 \mathrm{~nm}$ and $333 \mathrm{~nm}$. The absolute fluorescence quantum yield of $(S, \beta-D)-\mathbf{1}$ was valued to be 0.032 . The fluorescence responses to various metal ions including $\mathrm{Zn}^{2+}, \mathrm{Co}^{2+}, \mathrm{K}^{+}, \mathrm{Ag}^{+}, \mathrm{Ba}^{2+}, \mathrm{Mg}^{2+}, \mathrm{Ca}^{2+}, \mathrm{Cr}^{3+}, \mathrm{Ni}^{2+}, \mathrm{Cd}^{2+}, \mathrm{Cu}^{2+}, \mathrm{Al}^{3+}, \mathrm{Hg}^{2+}, \mathrm{Mn}^{2+}, \mathrm{Sr}^{2+}$ and $\mathrm{Pb}^{2+}$ in acetonitrile solution were recorded by the same fluorescence spectroscopy. The fluorescence measurement of $(S, \beta-D)-1$ was performed in $\mathrm{CH}_{3} \mathrm{CN}([(S, \beta-D)-1]=20 \mu \mathrm{M})$. As shown in Fig. 1 , it was clearly observed that none of other metal ions but $\mathrm{Cu}^{2+}$ exhibited obvious quenching fluorescence emission intensity under excited at $287 \mathrm{~nm}$ with the color changed from pale yellow to green. Upon the addition of copper, the characteristic color change of the detected solution implied the detection of copper ions over naked eye was feasible. The fluorescence emission intensity of $(S, \beta-D)-1$ at $\lambda=376 \mathrm{~nm}$ $(\lambda \mathrm{ex}=287 \mathrm{~nm})$ was almost entirely quenched by the coordination with cooper ion to form $1+1$ complex. The fluorescence intensity remained no variation when other different metal ions were added. All of these results were meant that $(S, \beta-D)-1$ could be potentially act as a $\mathrm{Cu}^{2+}$ fluorescence sensor in acetonitrile with high selectivity and sensitivity. The quenching fluorescence intensity upon the addition of $\mathrm{Cu}^{2+}$ ion to $(S, \beta-D)-1$ may be attributed to the intramolecular proton transfer through six-member ring transition state from phenolic hydroxyl groups to the adjacent $\mathrm{OCH}_{2}$ group in excited-state and owing to metal ion chelation which probably due to the photo-induced electron transfer (PET effect). It was indicated that two nitrogen atom of 1,2,3-triazole units on $(S, \beta-D)$-1 and the oxygen atom of BINOL offered the binding site to metal ion.

To further confirm the high selectivity of fluorescent sensor $(S, \beta-D)-1$ for discrimination $\mathrm{Cu}^{2+}$, the competition experiments were carried out as shown in Fig. 2. The fluorescent emission intensities were measured at $376 \mathrm{~nm}$ by the treatment of the mixture of 5.0 equiv other different metal ions mixed with 
same equiv. $\mathrm{Cu}^{2+}$ to the sensor $\left(20 \mu \mathrm{M}\right.$ in $\left.\mathrm{CH}_{3} \mathrm{CN}\right)$, respectively. It was observed that the fluorescence intensity of $(S, \beta-D)-1-\mathrm{Cu}^{2+}$ have scarce interference with other completive metal ions. Those meant the chiral sensor $(S, \beta-D)-1$ could be applied as a specific $\mathrm{Cu}^{2+}$ sensor with the tested background competitive ions.

\subsection{The complexation mechanism of $(S, \beta-D)-1$ and $C^{2+}$}

The dose-dependent fluorescence response of $(S, \beta-D)-1$ to $\mathrm{Cu}^{2+}$ and the fluorescence change induced by $\mathrm{Cu}^{2+} /$ EDTA were also measured at room temperature, as depicted in Fig. 3. According to the titration, the emission intensity at $376 \mathrm{~nm}$ decline gradually during the concentration of copper ion enlarged from 0 to 4.0 equiv, and it reach a low point upon the concentration of 4 equiv. It stated a good linear relationship between the maximal fluorescence intensity and the concentration of $\mathrm{Cu}^{2+}$. To demonstrate the coordination process between $(S, \beta-D)-1$ and $\mathrm{Cu}^{2+}$ was reversible or not, the chelating agent EDTA was added. The original fluorescence intensity did not lead back with the subsequent addition of an excess of EDTA, revealing that it was irreversible by the coordination of $(S, \beta-D)-1$ with $\mathrm{Cu}^{2+}$.

In order to confirm the binding affinity among $(S, \beta-D)-1$ and $\mathrm{Cu}^{2+}$, a graph of Job's plot was formed in acetonitrile by the reported method. The total concentration of the sensor and $\mathrm{Cu}^{2+}$ is $2.0 \times 10^{-5} \mathrm{M}$. The results depicted in Fig. 4A demonstrated the maximum value was found with the molar fraction of $\left[\mathrm{Cu}^{2+}\right] /\left([(S, \beta-D)-1]+\left[\mathrm{Cu}^{2+}\right]\right)$ was about 0.5 , proposing that $\mathrm{CH}_{2} \mathrm{BINOL}-\mathrm{Glucose}$ compound was bounded to $\mathrm{Cu}^{2+}$ by the formation of $1+1$ complex. The job's plot (Fig. 4B) was also the direct evidence to prove that 1:1 was the stoichiometry ratio of the new formed complex. In addition, the association constant $(\mathrm{Ka})$ between 1 with $\mathrm{Cu}^{2+}$ was calculated to be $2.70 \times 10^{4} \mathrm{~L} \mathrm{~mol}^{-1}$ by the Hildebrand-Benesi equation based on the plot of $\mathrm{F}_{0} /\left(\mathrm{F}_{0}-\mathrm{F}\right)$ versus $1 /\left[\mathrm{Cu}^{2+}\right](R=0.998)$. The detection limit (LOD) of the novel 3,3'-positions modified triazole-linked BINOL-Glucose sensor towards $\mathrm{Cu}^{2+}$ was calculated to be $3.14 \times 10^{-7} \mathrm{~mol} \mathrm{~L}^{-1}$ based on "LOD = $3 \sigma / \mathrm{s}$ " by the concentration-dependent fluorescence titration experiment (Fig. 4C).

Another evidence to determine the complex formed by 1:1 stoichiometry ratio according to ESI-MS spectra data (Fig. 5). A significant molecular ion peak of free $(S, \beta-D)-1$ was obtained at $m / z=1191.1$ which was offered by $\left[(S, \beta-D)-1+\mathrm{Na}^{+}\right]^{+}$. A new peak at $\mathrm{m} / \mathrm{z}=1231.6$ (calcad 1231.3) was observed corresponding to the formation of $\left[(S, \beta-D)-1-\mathrm{Cu}^{2+}\right]^{+}$when excess amounts of $\mathrm{Cu}^{2+}$ was added. The result supported our assumption that the formed $(S, \beta-D)-1^{-} \mathrm{Cu}^{2+}$ complex had a powerful binding affinity between the sensor and copper (II) ion. The binding mechanism between $S-1$ and $\mathrm{Cu}^{2+}$ was shown in Scheme 2.

To further investigate the complex mechanism between the sensor and $\mathrm{Cu}^{2+},{ }^{1} \mathrm{HNMR}$ titration experiments were performed in $\mathrm{CD}_{3} \mathrm{CN}$ as illustrated in Fig. 6 . to find out the further detailed binding information between $\mathrm{Cu}^{2+}$ with $(S, \beta-D)$-1. Upon different equivalents of $\mathrm{Cu}^{2+}$ (from 0 to 1 equiv.) was added, an obvious downshift of chemical shifts was observed until the amount of $\mathrm{Cu}^{2+}$ was over 1 equiv. 
The proton $\mathrm{H}_{\mathrm{d}}$ at $7.06 \mathrm{ppm}$ assigned to phenolic hydroxyl disappeared totally when $\mathrm{Cu}^{2+}$ was added to the solution of the sensor, indicating that the oxygen atom in phenolic hydroxyl was connected with the coordination between $\mathrm{Cu}^{2+}$ and $(S, \beta-D)$-1. But proton $\mathrm{H}_{\mathrm{a}}$ of the 1,2,3-triazole rings exhibited a remarkable downshift $\Delta \delta=0.11 \mathrm{ppm}$ from $8.07 \mathrm{ppm}$ to $8.18 \mathrm{ppm}$, indicating copper ion were bound to the nitrogen atoms of the 1,2,3-triazole group. The nuclear magnetic peaks $\mathrm{H}_{\mathrm{c}}$ - $-\mathrm{OCH}_{2}$ - linking 1,2,3-triazole groups were represented weak upfield shifts from $4.80 \mathrm{ppm}$ to $4.76 \mathrm{ppm}$. The results demonstrated that $\mathrm{Cu}^{2+}$ was selectively coordinated with $-\mathrm{OCH}_{2}$ - and 1,2,3-triazole rings. Tetrahedron complex may be formed by copper ions as the center. The consequences provided by mass, fluorescence titration and NMR spectroscopic analyses were all illustrated the $1+1$ binding model was formed between the BINOLtraizole-glucose compound and copper ion.

The IR spectrum was also used to identify the binding site as illustrated in Fig. 7. Phenolic hydroxyl exhibited a strong single absorption band at $1227 \mathrm{~cm}^{-1}$, according to the weak hydrogen-bonding interaction with the adjacent $\mathrm{OCH}_{2}$ group. The absorption bands of phenolic hydroxyl in the 1:1 complex of $\mathrm{Cu}^{2+}$ was weaken sharply, indicating that oxygen of phenolic hydroxyl was coordinated with $\mathrm{Cu}^{2+}$. Another proof was the absorption band of 1,2,3-triazole at $1627 \mathrm{~cm}^{-1}$ and $1369 \mathrm{~cm}^{-1}$ changed to very strong in the 1:1 complex, suggesting nitrogen of 1,2,3-triazole was also coordinated with $\mathrm{Cu}^{2+}$.

\section{Conclusions}

A novel $\mathrm{Cu}^{2+}$-selective fluorescence sensor was designed and synthesized by click reaction of glucose azide and BINOL chromophore with high sensitivity and selectivity with scarce interference of other completive metal ions. $\mathrm{Cu}^{2+}$ exhibited obvious quenching fluorescence emission intensity under excited at $287 \mathrm{~nm}$ with the color changed from pale yellow to green. The new BINOL-Glucose derivative show a 1:1 stoichiometry with high binding constants and a low detection limit. The $\mathrm{Cu}^{2+}{ }^{2+}$-induced fluorescence quenching may be attributed to the intramolecular proton transfer through six-member ring transition state from phenolic hydroxyl groups to the adjacent $\mathrm{OCH}_{2}$ group in excited-state and a PET effect of the copper $1+1$ complex.

\section{Experiments}

\subsection{General Reagents and apparatus}

All the analytical grade solvents were distilled before used. Materials were supplied by reagent suppliers or provided by our laboratory's synthesis through the known routes and no further purification before used. If no otherwise specified, the reagents applied in the chiral synthesis were optical purity. The corresponding metallic nitrates were used to prepare the various metal ions $(0.1 \mathrm{M})$ by their solution in distilled-deionized water, while $\mathrm{K}^{+}, \mathrm{Hg}^{2+}, \mathrm{Mn}^{2+}$, and $\mathrm{Ba}^{2+}$ were used by chloride solution). $\mathrm{Cu}\left(\mathrm{NO}_{3}\right)_{2} \cdot\left(\mathrm{H}_{2} \mathrm{O}\right)_{2.5}$ was used as the $\mathrm{Cu}^{2+}$ source unless otherwise noted. ETDA solution $(1.0 \mathrm{mmol})$ was 
prepared by the solution of ethylene diaminetetraacetic acid disodium salt (Na2EDTA) $(1.0 \mathrm{mmol})$ in deionized water $(10 \mathrm{ml}) .{ }^{1} \mathrm{HNMR}$ and ${ }^{13} \mathrm{CNMR}$ were determined by a Bruker AM-400WB spectrometer with internal tetramethylsilane (TMS) and $\mathrm{CDCl}_{3}$ or $\mathrm{CD}_{3} \mathrm{CN}$ as solvents. Infrared spectra (IR) were measured on a L1600301 Spectrum TWO FT-IR spectrometer. Absorption spectra were recorded on an Agilent 8453 UVVis spectrometer. Fluorescence emission spectra were recorded by a Hitachi F-4500 and a Hitachi F-4600 fluorescence spectrometer unless noted othervise. An Absolute PL Quantum Yield Spectrometer C11347 was applied to measure the fluorescence quantum yield. ESI-MS spectral data were recorded with a Bruker amazon SL Ion Trap Mass spectrometer. AWRS-1B melting point apparatus was used to measure melting points. A Rudolph AUTOPOL IV automatic polarimeter was used to measure the optical rotation.

\subsection{Methods}

A $20 \mu \mathrm{M}$ stock solution of sensor in acetonitrile and stock solution of metal ions ( $0.1 \mathrm{mM}$ in deionized water) were freshly prepared to test each process. For every fluorescent quenching measurement, appropriate amounts of $\mathrm{Cu}^{2+}$ stock solution was mixed with the sensor solution in a $2 \mathrm{~mL}$ quartz cuvette at room temperature. The competition experiments were mixed appropriate metal ions solution with $\mathrm{Cu}^{2+}$ in the same concentration $(20 \mu \mathrm{M})$. Job's plot and the association constant was gained by the record on the fluorescence emission towards different concentration of copper ion. $\mathrm{Cu}\left(\mathrm{NO}_{3}\right)_{2} \cdot\left(\mathrm{H}_{2} \mathrm{O}\right)_{2.5}(0.1 \mathrm{M}$ in $\left.D_{2} O\right)$ was added dropwise to the NMR tube containing sensor $\left(C_{3} C N, 0.4 \mathrm{~mL}, 25 \mathrm{mM}\right)$ to get 1:0, 1:0.3, 1:0.7, and 1:1 stoicheiometry of the sensor: $\mathrm{Cu}^{2+}$.

\subsection{Synthesis}

Synthesis of (S)-2,2'-bis(methoxymethoxy)-3,3'-bis(hydroxymethyl)-1,1'-binaphthol (S-3) (S)-2,2'bis(methoxymethoxy)-3,3'-diformyl-1,1'-binaphthol (S-2) $(5.2 \mathrm{~g}, 12.1 \mathrm{mmol})$ was disolved in $\mathrm{CH}_{3} \mathrm{OH}$ :THF = 2:3 solution $(20 \mathrm{ml})$ under ice-cooling. $\mathrm{NaBH}_{4}(1.82 \mathrm{~g}, 47.9 \mathrm{mmol})$ was added in little portions and stirred at room temperature for $12 \mathrm{~h}$. After quenched by saturated salt water, the mixture was extracted with ethyl acetate. The combined organic phase was then washed with brine and dried over anhydrous magnesium sulfate. After removal the solvent, $5.1 \mathrm{~g}$ pale yellow oil was obtained ( $97 \%$ yield). ${ }^{1} \mathrm{H} \mathrm{NMR}(400 \mathrm{MHz}$, $\left.\mathrm{CDCl}_{3}\right) \delta 8.04(\mathrm{~s}, 1 \mathrm{H}), 7.91(\mathrm{~d}, J=8.2 \mathrm{~Hz}, 1 \mathrm{H}), 7.43(\mathrm{t}, J=7.4 \mathrm{~Hz}, 1 \mathrm{H}), 7.32-7.23(\mathrm{~m}, 1 \mathrm{H}), 7.17(\mathrm{~d}, J=8.5$ $\mathrm{Hz}, 1 \mathrm{H}), 4.93(\mathrm{dd}, J=51.5,12.7 \mathrm{~Hz}, 2 \mathrm{H}), 4.48(\mathrm{dd}, J=14.3,6.1 \mathrm{~Hz}, 2 \mathrm{H}), 3.17(\mathrm{~s}, 3 \mathrm{H}) .{ }^{13} \mathrm{C} \mathrm{NMR}(100 \mathrm{MHz}$, $\left.\mathrm{CDCl}_{3}\right) \delta 153.1,134.7,133.9,131.1,129.7,128.3,126.9,125.93,125.5,125.399 .4,61.9,57.2$ (ppm).

Synthesis of (S)-2,2'-bis(methoxymethoxy)-3,3'-bis(O-Propargyloxymethyl)-1,1'-binaphthol (S-4)

A stirred solution of $S-3(2.5 \mathrm{~g}, 5.75 \mathrm{mmol})$ dissolved in anhydrous THF $(40 \mathrm{~mL})$ at $0^{\circ} \mathrm{C}$ under nitrogen, and $\mathrm{NaH}(0.6 \mathrm{~g}, 25.0 \mathrm{mmol})$ was added in little portions. 3-Bromo-1-propyne $(2.5 \mathrm{~mL}, 29 \mathrm{mmol})$ were added dropwise. The reaction was stirred overnight, and warmed to room temperature. Quenched with water slowly. Extracted with ethyl acetate, washed with brine and dried over $\mathrm{Na}_{2} \mathrm{SO}_{4}$. The crude product was purified by a silica column using 1:1 hexane: EtOAc to afford compound as a yellow oil $(2.64 \mathrm{~g}, 90 \%$ yield). ${ }^{1} \mathrm{H}$ NMR $\left(400 \mathrm{MHz}, \mathrm{CDCl}_{3}\right) \delta 8.26(\mathrm{~s}, 1 \mathrm{H}), 8.07(\mathrm{~d}, J=8.1 \mathrm{~Hz}, 1 \mathrm{H}), 7.58(\mathrm{t}, J=7.3 \mathrm{~Hz}, 1 \mathrm{H}), 7.43(\mathrm{t}, J=$ 
$7.5 \mathrm{~Hz}, 1 \mathrm{H}), 7.37(\mathrm{~d}, J=8.4 \mathrm{~Hz}, 1 \mathrm{H}), 5.13(\mathrm{~s}, 2 \mathrm{H}), 4.79(\mathrm{~d}, J=5.7 \mathrm{~Hz}, 1 \mathrm{H}), 4.68(\mathrm{~d}, J=5.7 \mathrm{~Hz}, 1 \mathrm{H}), 4.54(\mathrm{~d}, J$ $=1.9 \mathrm{~Hz}, 2 \mathrm{H}), 3.02(\mathrm{~s}, 3 \mathrm{H}), 2.68(\mathrm{~s}, 1 \mathrm{H}) .{ }^{13} \mathrm{C} N M R\left(100 \mathrm{MHz}, \mathrm{CDCl}_{3}\right) \delta 152.1,133.8,131.1,130.7,129.1$, $128.0,126.5,126.1,125.3,99.4,79.7,74.8,67.7,57.9,56.6(\mathrm{ppm})$.

Synthesis of (S)-3,3'-bis(O-Propargyloxymethyl)-1,1'-binaphthol. (S-5)

A mixture of $S-4(1.0 \mathrm{~g}, 2.0 \mathrm{mmol})$, methanol $(40 \mathrm{~mL})$ and THF $(60 \mathrm{ml})$ and con. $\mathrm{HCl}(15 \mathrm{~mL})$ were stirred at at room temperature for $3 \mathrm{~h}$. After quenched the reaction by $\mathrm{H}_{2} \mathrm{O}$ slowly, the resulting residue was extracted with ethyl acetate, washed with brine and dried over $\mathrm{Na}_{2} \mathrm{SO}_{4}$. After filtered, evaporation of the solvent to obtain the desired product $(0.7 \mathrm{~g}, 85 \%)$ as a brown oil. ${ }^{1} \mathrm{H} \mathrm{NMR}\left(400 \mathrm{MHz}, \mathrm{CDCl}_{3}\right) \delta 7.92(\mathrm{~s}, 1 \mathrm{H})$, $7.83(\mathrm{~d}, J=8.0 \mathrm{~Hz}, 1 \mathrm{H}), 7.30(\mathrm{t}, J=7.3 \mathrm{~Hz}, 1 \mathrm{H}), 7.21(\mathrm{~d}, J=6.5 \mathrm{~Hz}, 2 \mathrm{H}), 7.07(\mathrm{~d}, J=8.4 \mathrm{~Hz}, 1 \mathrm{H}), 5.95(\mathrm{~s}, 1 \mathrm{H})$, $4.92(\mathrm{~s}, 2 \mathrm{H}), 4.30(\mathrm{~s}, 2 \mathrm{H}), 2.46(\mathrm{~s}, 1 \mathrm{H}) .{ }^{13} \mathrm{C}$ NMR $\left(100 \mathrm{MHz}, \mathrm{CDCl}_{3}\right) \delta 150.0,132.4,128.4,127.9,127.2$, $126.1,124.4,123.4,123.0,112.1,78.2,74.2,67.6,56.8$ (ppm).

Synthesis of ( $\mathrm{S}, \beta$-D )-1. 2,3,4,6-Tetra-O-acetyl-beta-D-glucopyranosyl azide (1.09 g,2.92 mmol)and S-5 $(0.41 \mathrm{~g} \otimes 0.97 \mathrm{mmol})$ were added to a stirred $42 \mathrm{~mL}$ THF at $273 \mathrm{~K}$ under a argon atmosphere. Sodium ascorbate $\varangle 0.43 \mathrm{~g} \otimes 2.14 \mathrm{mmol} \rrbracket, \mathrm{CuSO}_{4} .5 \mathrm{H}_{2} \mathrm{O} \otimes 0.25 \mathrm{~g} \otimes 0.98 \mathrm{mmol} \square$ and $\mathrm{H}_{2} \mathrm{O}(8 \mathrm{~mL})$ were added in turn slowly. The mixture was stirred room temperature for $12 \mathrm{~h}$ under argon. After the reaction finished, the mixture was poured into $100 \mathrm{~mL}$ ice-water, extracted with EtOAc, washed with brine and dried over anhydrous $\mathrm{MgSO}_{4}$. The combined filter concentrated, the crude product was purified directly by column chromatography on silica by using petroleum ether: EtOAc $=1$ : 1 as the eluent to provide a pale solid ( $\mathrm{S}$, $\beta$ D)-1 (0.63 g, 46\%). [a $]_{D}^{25}=-29.0\left(\mathrm{c}=1 \mathrm{CH}_{3} \mathrm{CN}\right) . \mathrm{Mp} 129-131^{\circ} \mathrm{C}$. IR (KBr) 3435, 3151, 2960, 2125, 1754, $1627,1369,1227,1106,1030,803 \mathrm{~cm}^{-1} ;{ }^{1} \mathrm{H}$ NMR $\left(400 \mathrm{MHz}, \mathrm{CDCl}_{3}\right) \delta 7.93(\mathrm{~s}, 1 \mathrm{H}), 7.90-7.79(\mathrm{~m}, 2 \mathrm{H})$, $7.31(\mathrm{t}, J=7.2 \mathrm{~Hz}, 1 \mathrm{H}), 7.22(\mathrm{t}, J=7.4 \mathrm{~Hz}, 1 \mathrm{H}), 7.08(\mathrm{~d}, J=8.1 \mathrm{~Hz}, 1 \mathrm{H}), 5.86(\mathrm{~d}, J=7.6 \mathrm{~Hz}, 1 \mathrm{H}), 5.50-5.34$ $(\mathrm{m}, 2 \mathrm{H}), 5.23(\mathrm{t}, J=7.9 \mathrm{~Hz}, 1 \mathrm{H}), 4.90(\mathrm{~s}, 2 \mathrm{H}), 4.83(\mathrm{~s}, 2 \mathrm{H}), 4.26(\mathrm{~d}, J=12.4 \mathrm{~Hz}, 1 \mathrm{H}), 4.11(\mathrm{~d}, J=12.4 \mathrm{~Hz}, 1 \mathrm{H})$, $3.98(\mathrm{~d}, J=7.3 \mathrm{~Hz}, 1 \mathrm{H}), 2.03$ (d, $J=17.4 \mathrm{~Hz}, 10 \mathrm{H}), 1.79(\mathrm{~s}, 2 \mathrm{H}) .{ }^{13} \mathrm{C} \mathrm{NMR}\left(100 \mathrm{MHz}, \mathrm{CDCl}_{3}\right) \delta 170.4,169.8$, 169.3, 168.9, 151.3, 145.5, 133.6, 129.4, 128.9, 128.2, 126.9, 125.8, 124.5, 123.8, 121.2, 113.3, 85.7, 75.1, 72.6, 70.4, 69.2 67.8, 63.5, 61.5, 20.7-20.3, 20.0 (ppm). MS (ESI-): calcd for $\left[\mathrm{C}_{56} \mathrm{H}_{60} \mathrm{~N}_{6} \mathrm{O}_{22}-\mathrm{H}\right]^{-}$1168.3; found 1167.2.

\section{Declarations}

\section{Acknowledgements}

The authors are grateful for the financial support of the National Natural Science Foundation of China (No.21462018), the Science Fund of the Technology Office of Jiangxi, China (20192BAB203003) and Jiangxi Science and Technology Normal University Program for Graduate Innovation Fund (YC2020-X21).

\section{Funding}


This Study Was Supported by the financial support of the National Natural Science Foundation of China (No.21462018).

\section{Affiliations}

Jiangxi Key Laboratory of Organic Chemistry, Jiangxi Science \& Technology Normal University, Nanchang 330013, China

Huizhen Wang, Yang Liu and Xiaoxia Sun

College of Chemistry, Nanchang University, Nanchang, 330031, PR China

Yu Hu

Availability of Data and Material (Data Transparency) Not applicable.

Code Availability (Software Application or Custom Code) Not applicable.

\section{Contributions}

Xiaoxia Sun and Yu Hu designed the methodology for the research experiment and wrote the paper, analyzed most of the data and wrote the paper; Huizhen Wang and Yang Liu performed the research and carried out additional analyses.

Conflicts of Interest. The authors decare no conflict of interest.

\section{References}

1. Huo, F. J. et al. X. A rhodamine-based dual chemosensor for the visual detection of copper and the ratiometric fluorescent detection of vanadium. Dyes. Pigments, 86, 50-55 (2010).

2. Brown, D. R. \& Kozlowski, H. Biological inorganic and bioinorganic chemistry of neurodegeneration based on prion and Alzheimer diseases. Dalton. Trans, 13, 1907-1917 (2004).

3. Qu, L., Yin, C., Huo, F., Zhang, Y. \& Li, Y. A commercially available fluorescence chemosensor for copper ion and its application in bioimaging. Sens. Actuators. B, 183, 636-640 (2013).

4. Su, J., Sun, Y. Q., Huo, F. J., Yang, Y. T. \& Yin, C. X. Naked-eye determination of oxalate anion in aqueous solution with copper ion and pyrocatechol violet. Analyst, 135, 2918-2923 (2010).

5. Gorla, L., Martí-Centelles, V., Altava, B., Burguete, M. I. \& Luis, S. V. Cu2 + recognition by N, N'benzylated bis (amino amides). Dalton. T, 46, 2660-2669 (2017).

6. Verbelen, B. et al. Efficient two-step synthesis of water soluble BODIPY-TREN chemosensors for copper (II) ion. RSC. Adv, 7, 3066-3071 (2017).

7. Paul, P. et al. Functionalized calix[4]arene as colorimetric dual sensor for $\mathrm{Cu}(\mathrm{II})$ and cysteine in aqueous media: Experimental and computational study. New. J. Chem, 41, 12541-12553 (2017). 
8. Qi, X. et al. New BODIPY derivatives as OFF - ON fluorescent chemosensor and fluorescent chemodosimeter for Cu2+: cooperative selectivity enhancement toward Cu2+. J. Org. Chem, 71, 2881-2884 (2006).

9. Tan, W. B. et al. A novel coumarin-based fluorescence enhancement and colorimetric probe for $\mathrm{Cu} 2+$ via selective hydrolysis reaction. J. Photoch. Photobio. A, 324, 81-86 (2016).

10. Huo, F. et al. The synthesis, characterization of three isomers of rhodamine derivative and their application in copper (II) ion recognition. Sens. Actuators. B, 188, 735-740 (2013).

11. Wang, Z., Wang, M., Wu, G., Wu, D. \& Wu, A. Colorimetric detection of copper and efficient removal of heavy metal ions from water by diamine-functionalized SBA-15. Dalton. Trans, 43, 8461-8468 (2014).

12. Gaggelli, E., Kozlowski, H., Valensin, D. \& Valensin, G. Copper Homeostasis and Neurodegenerative Disorders (Alzheimer's, Prion, and Parkinson's Diseases and Amyotrophic Lateral Sclerosis). Chem. Rev, 106, 1995-2044 (2006).

13. Xu, M., Yin, C., Huo, F., Zhang, Y. \& Chao, J. A highly sensitive "ON-OFF-ON" fluorescent probe with three binding sites to sense copper ion and its application for cell imaging. Sens. Actuators. B, 204, 18-23 (2014).

14. Wang, Z. et al. S. A novel hexahydroquinazolin-2-amine-based fluorescence sensor for Cu2 + from isolongifolanone and its biological applications. RSC. Adv, 7, 33263-33272 (2017).

15. Sai, L. et al. Protein-derived carbon nanodots with an ethylenediamine-modulated structure as sensitive fluorescent probes for Cu2 + detection. RSC. Adv, 7, 16608-16615 (2017).

16. Wang, Y. et al. Colorimetric probe for copper(II) ion detection based on cost-effective aminoquinoline derivative. Anal. Methods, 9, 1727-1731 (2017).

17. Liu, C., Jiao, X., He, S., Zhao, L. \& Zeng, X. A highly selective and sensitive fluorescent probe for Cu2 + based on a novel naphthalimide-rhodamine platform and its application in live cell imaging. Org. Biomol. Chem, 15, 3947-3954 (2017).

18. Chaignon, V., Quesnoit, M. \& Hinsinger, P. Copper availability and bioavailability are controlled by rhizosphere $\mathrm{pH}$ in rape grown in an acidic Cu-contaminated soil. Environ. Pollut, 157, 3363-3369 (2009).

19. Georgopoulos, P. G., Roy, A., Yonone-Lioy, M. J., Opiekun, R. E. \& Lioy, P. J. Environmental copper: its dynamics and human exposure issues. J. Toxicol. Env. Heal. B, 4, 341-394 (2001).

20. Liao, Z., Wang, D., Zheng, J. Q., Tan, H. W. \& Zheng, X. J. Jin, L. P. A single chemosensor for bimetal $\mathrm{Cu}$ (ii) and $\mathrm{Zn}$ (ii) in aqueous medium. RSC. Adv, 6, 33798-33803 (2016).

21. Wang, C. et al. Enantioselective Fluorescent Recognition in Fluorous Phase: Enhanced Reactivity and Expanded Chiral Recognition. J. Am. Chem. Soc, 137, 3747-3750 (2015).

22. Li, H. et al. Real time detection and imaging of copper (II) in cellular mitochondria. Org. Biomol. Chem, 15, 598-604 (2017). 
23. Thirumalaivasan, N., Venkatesana, P. \& Wu, S. Highly selective turn-on probe for $\mathrm{H} 2 \mathrm{~S}$ with imaging applications in vitro and in vivo. New. J. Chem, 41, 13510-13515 (2017).

24. Fu, Y. et al. Two-photon ratiometric fluorescent sensor based on specific biomolecular recognition for selective and sensitive detection of copper ions in live cells. Anal. Chem, 85, 11936-11943 (2013).

25. Geng, T. M., Wu, D. Y. \& Huang, W. Dual turn-on fluorescent chemosensor for Cu2 + and $\mathrm{Hg} 2+$ in aqueous medium based on a water-soluble polyacrylamide containing rhodamine. J. Polym. Res, 22, 40 (2015).

26. Wu, C. et al. Rhodamine Scaffold. Switching the Recognition Preference by Adding One Atom. Org. Lett, 14, 4198-4201 (2012). Ring Expansion of Spiro-thiolactam in

27. Huang, C. B., Li, H. R., Luo, Y. \& Xu, L. A naphthalimide-based bifunctional fluorescent probe for the differential detection of $\mathrm{Hg} 2+$ and $\mathrm{Cu} 2+$ in aqueous solution. Dalton. Trans, 43, 8102-8108 (2014).

28. Hu, Z. Q., Sun, L. L., Gu, Y. Y. \& Jiang, Y. A sensitive and selective fluorescent probe for detection of glutathione in the presence of $\mathrm{Cu} 2+$ and its application to biological imaging. Sens. Actuators. $B$, 212, 220-224 (2015).

29. You, Q. H., Lee, A. W. M., Chan, W. H., Zhu, X. M. \& Leung, K. C. F. A coumarin-based fluorescent probe for recognition of $\mathrm{Cu} 2+$ and fast detection of histidine in hard-to-transfect cells by a sensing ensemble approach. Chem. Commun, 50, 6207-6210 (2014).

30. Kursunlu, A. N., Koc, Z. E., Obalı, A. Y. \& Güle, E. A symmetric and selective fluorescent Cu (II) sensor based on bodipy and s-triazine. Journal of Luminescence, 149, 215-220 (2014).

31. Kursunlu, A. N., Sahin, E. \& Güle, E. Cu (II) Chemosensor Based on a Fluorogenic Bodipy-Salophen Combination: Sensitivity and Selectivity Studies. Journal of fluorescence, 26 (6), 1997-2004 (2016).

32. Yao, P. S., Cao, Q. Y., Peng, R. P. \& Liu, J. H. Quinoline-functionalized norbornene for fluorescence recognition of metal ions. J. Photochem. Photobiol. A, 305, 11-18 (2015).

33. Zhang, J. F. et al. Naphthalimide modified rhodamine derivative: ratiometric and selective fluorescent sensor for Cu2 + based on two different approaches. Org. Lett, 12, 3852-3855 (2010).

34. $\mathrm{Pu}, \mathrm{L}$. Simultaneous Determination of Concentration and Enantiomeric Composition in Fluorescent Sensing. Chem. Res, 50, 1032-1040 (2017).

35. Pugh, V., Hu, Q. S. \& Pu, L. The First Dendrimer-Based Enantioselective Fluorescent Sensor for the Recognition of Chiral Amino Alcohols. Angew. Chem. Int. Ed, 39, 3638-3641 (2000).

36. Lin, J., Hu, Q. S., Xu, M. H. \& Pu, L. A. Practical Enantioselective Fluorescent Sensor for Mandelic Acid. J. Am. Chem. Soc, 124, 2088-2089 (2002).

37. Xu, M. H., Lin, J., Hu, Q. S. \& Pu, L. Fluorescent Sensors for the Enantioselective Recognition of Mandelic Acid: Signal Amplification by Dendritic Branching. J. Am. Chem. Soc, 124, 14239-14246 (2002).

38. Li, Z. B., Lin, J. \& Pu, L. A. Cyclohexyl-1,2-diamine-derived Bis(binaphthyl) Macrocycle: Enhanced Sensitivity and Enantioselectivity in the Fluorescent Recognition of Mandelic Acid. Angew. Chem. Int. $E d, 44,1690-1693$ (2005). 
39. Liu, H. L., Hou, X. L. \& Pu, L. Enantioselective Precipitation and Solid-State Fluorescence Enhancement in the Recognition of alpha-Hydroxycarboxylic Acids. Angew. Chem. Int. Ed, 48, 382385 (2009).

40. Liu, H. L. et al. Pu, L. Highly Enantioselective Recognition of Structurally Diverse alphaHydroxycarboxylic Acids using a Fluorescent Sensor. Angew. Chem. Int. Ed, 49, 602-606 (2010).

41. Chen, X. et al. Enantioselective Gel Collapsing: A New Means of Visual Chiral Sensing. J. Am. Chem. Soc, 132, 7297-7299 (2010).

42. Yu, S. \& Pu, L. Pseudoenantiomeric Fluorescent Sensors in a Chiral Assay. J. Am. Chem. Soc, 132, 17698-17700 (2010).

43. Pu, L. \& Enantioselective Fluorescent Sensors A Tale of BINOL. Acc. Chem. Res. 45, 150 - 163(2012).

44. Hu, L. L., Yu, S. S., Wang, Y. C., Yu, X. Q. \& Pu, L. Enhanced Fluorescence of 3,3'-Diformyl BINOL by Functional Secondary Amines. Org. Lett, 19, 3779-3782 (2017).

45. Zeng, C. Y., Zhang, X. L. \& Pu, L. Enhanced Enantioselectivity in the Fluorescent Recognition of a Chiral Diamine by Using a Bisbinaphthyl Dialdehyde. ACS. Omega, 3, 12545-12548 (2018).

46. Zhao, F. et al. Enantioselective Fluorescent Recognition of Amino Acids in Aqueous Solution by Using a Chiral Aldehyde Probe. Eur. J. Org. Chem, 16, 1891-1895 (2018).

47. Song, T., Cao, Y., Zhao, G. \& Pu, L. Fluorescent Recognition of Zn2 + by Two Diastereomeric Salicylaldimines: Dramatically Different Responses and Spectroscopic Investigation. Inorg. Chem, 56, 4395-4399 (2017).

48. Huang, Z., Yu, S. S., Yu, X. Q., Pu, L. \& Wen, K. Zn(II) Promoted Dramatic Enhancement in the Enantioselective Fluorescent Recognition of Chiral Amines by a Chiral Aldehyde. Chem. Sci, 5, 34573462 (2014).

49. Huang, Z. et al. Convenient Fluorescent Method to Simultaneously Determine the Enantiomeric Composition and Concentration of Functional Chiral Amines. Chem. Eur. J, 20, 16458-16461 (2014).

50. Zhang, X. P. et al. Conjugated polymer-enhanced enantioselectivity in fluorescent sensing. Chem. Sci, 7, 3614-3620 (2016).

51. Yu, S., Plunkett, W., Kim, M. \& Pu, L. Simultaneous Determination of Both the Enantiomeric Composition and Concentration of a Chiral Substrate with One Fluorescent Sensor. J. Am. Chem. Soc, 134, 20282-20285 (2012).

52. Yu, S. S. et al. Molecular Recognition of Aliphatic Diamines by 3,3'-Di(trifluoroacetyl)-1,1'-bi-2naphthol. J. Org. Chem. 78, 12671 - 12680(2013).

53. Wen, L. K. et al. Rational Design of a Fluorescent Sensor to Simultaneously Determine Both the Enantiomeric Composition and Concentration of Chiral Functional Amines. J. Am. Chem. Soc, 137, 4517-4524 (2015).

54. Wang, C. et al. Enantioselective Fluorescent Recognition in the Fluorous Phase: Enhanced Reactivity and Expanded Chiral Recognition. J. Am. Chem. Soc, 137, 3747-3750 (2015). 
55. Liu, X. C., Yang, X., Fu, Y. \& Zhu, C. J. A fluorescent sensor for $\mathrm{Hg} 2+$ and $\mathrm{Ag}+$ functions as a molecular switch based on click-generated triazole moiety. Tetrahedron. Letters, 52, 2295-2298 (2011).

56. Ni, X. L., Zeng, X., Redshaw, C. \& Yamato, T. Synthesis and evaluation of a novel pyrenyl-appended triazole-based thiacalix[4]arene as a fluorescent sensor for Ag + ion. Tetrahedron, 67, 3248-3253 (2011).

57. Lin, L., Shen, Q., Chen, R. G. \& Juan, X. Synthesis of triazole-linked $\beta$-C-glycosyl dimers as inhibitors of PTP1B. Bioorg. Med. Chem, 16, 9757-9763 (2008).

58. Zhang, J. Y. et al. Triazole-linked benzylated glucosyl, galactosyl, and mannosyl monomers and dimers as novel sugar scaffold-based PTP1B inhibitors. Chem. Lett, 39, 1261-1263 (2010).

59. Yang, J. W. et al. Microwave-accelerated click chemistry: expeditious synthesis of novel triazolelinked salicylic $\beta$-DO-glycosides with PTP1B inhibitory activity. Bull. Korean. Chem. Soc, 31, 33593365 (2010).

60. Song, Z. et al. Preparation of triazole-linked glycosylated a-ketocarboxylic acid derivatives as new PTP1B inhibitors. Carbohydr. Res, 346, 140-145 (2011).

61. Maisoneuve, S. \& Metivier, R. Synthesis of Bispyrenyl Sugar-Aza-Crown Ethers as New Fluorescent Molecular Sensors for Cu(II). J. Org. Chem, 72, 5980-5985 (2007).

62. Hsieh, Y. C., Chir, J. L., Wu, H. H. \& Wu, A. T. Synthesis of a sugar-aza-crown ether-based cavitand as a selective fluorescent chemosensor for Cu2 + ion. Tetrahedron Lett, 51, 109-111 (2010).

63. He, P. X. \& Song, Z. Creation of 3,4-bis-triazolocoumarin-sugar conjugates via flourogenic dual click chemistry and their quenching specificity with silver $(\mathrm{I})$ in aqueous media. Tetrahedron, 67, 33433347 (2011).

64. He, P. X. et al. Microwave-assisted construction of triazole-linked amino acid-glucoside conjugates as novel PTP1B inhibitors. New. J. Chem, 35, 622-631 (2011).

65. Rajakumar, R., Anandhan, R. \& Kalpana, V. Click chemistry approach for the synthesis of watersoluble glycodendrimer with triazole as building unit. Synlett, 9, 1417-1422 (2009).

66. Hu, Y., Shen, H. Y., Zhang, X. H., Liu, Y. \& Sun, X. X. A Novel Sensitive and Selective Fluorescent Chemosensor for Ag+ based on BINOL-Glucose Derivative and Spectroscopic Investigation. RSC. adv, 8, 23252-23256 (2018).

\section{Figures}




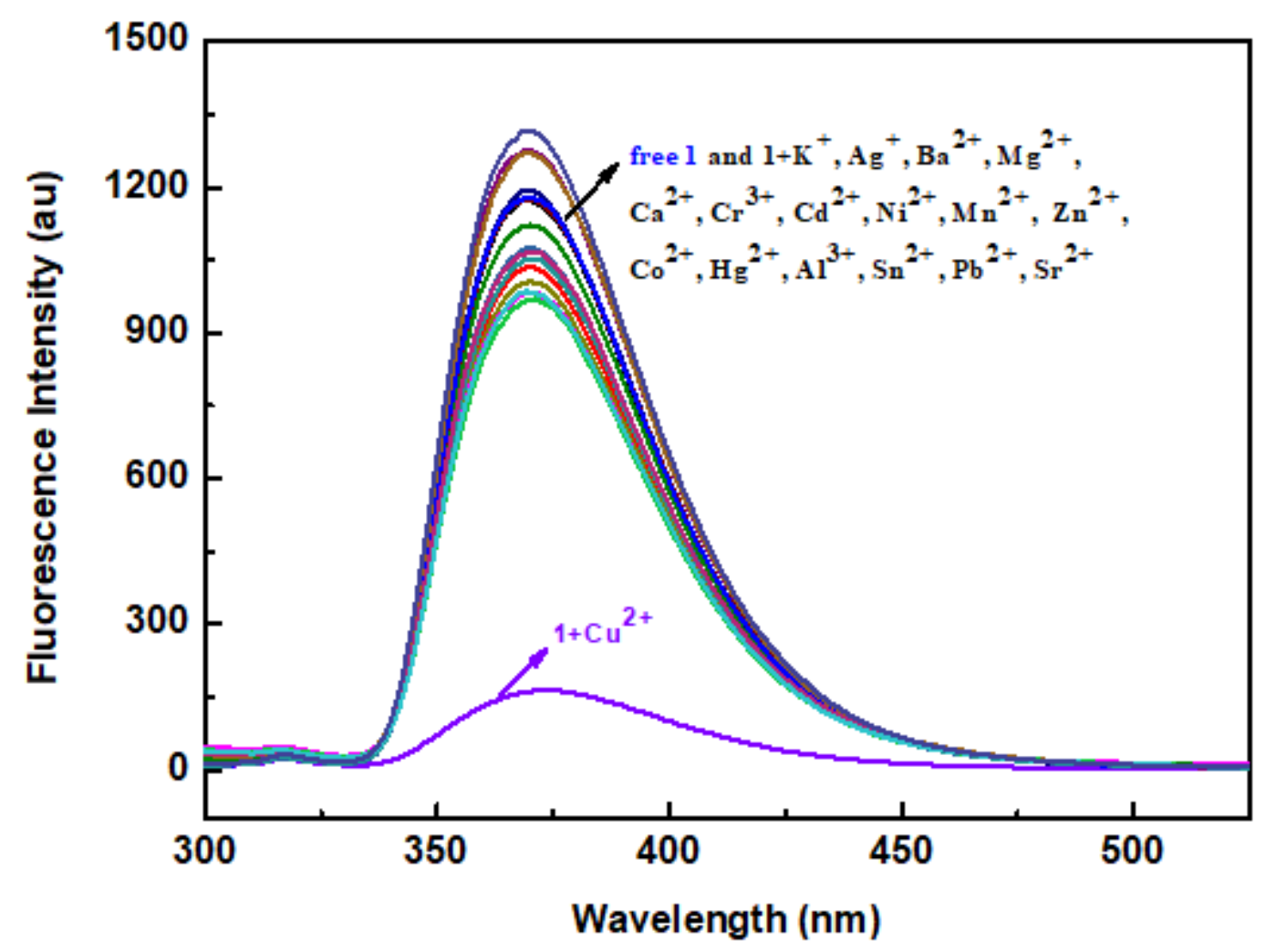

Figure 1

Fluorescence spectra of $(\mathrm{S}, \beta-\mathrm{D})-1(20 \mu \mathrm{M}$ in $\mathrm{CH} 3 \mathrm{CN})$ in presence of various ions such as $\mathrm{Zn} 2+, \mathrm{Co} 2+, \mathrm{K}+$, $\mathrm{Ag}+, \mathrm{Ba} 2+, \mathrm{Mg} 2+, \mathrm{Ca} 2+, \mathrm{Cr} 3+, \mathrm{Ni} 2+, \mathrm{Cd} 2+, \mathrm{Cu} 2+, \mathrm{Al} 3+, \mathrm{Hg} 2+, \mathrm{Mn} 2+, \mathrm{Sr} 2+$ and $\mathrm{Pb} 2+$ ions (5 equiv.). 


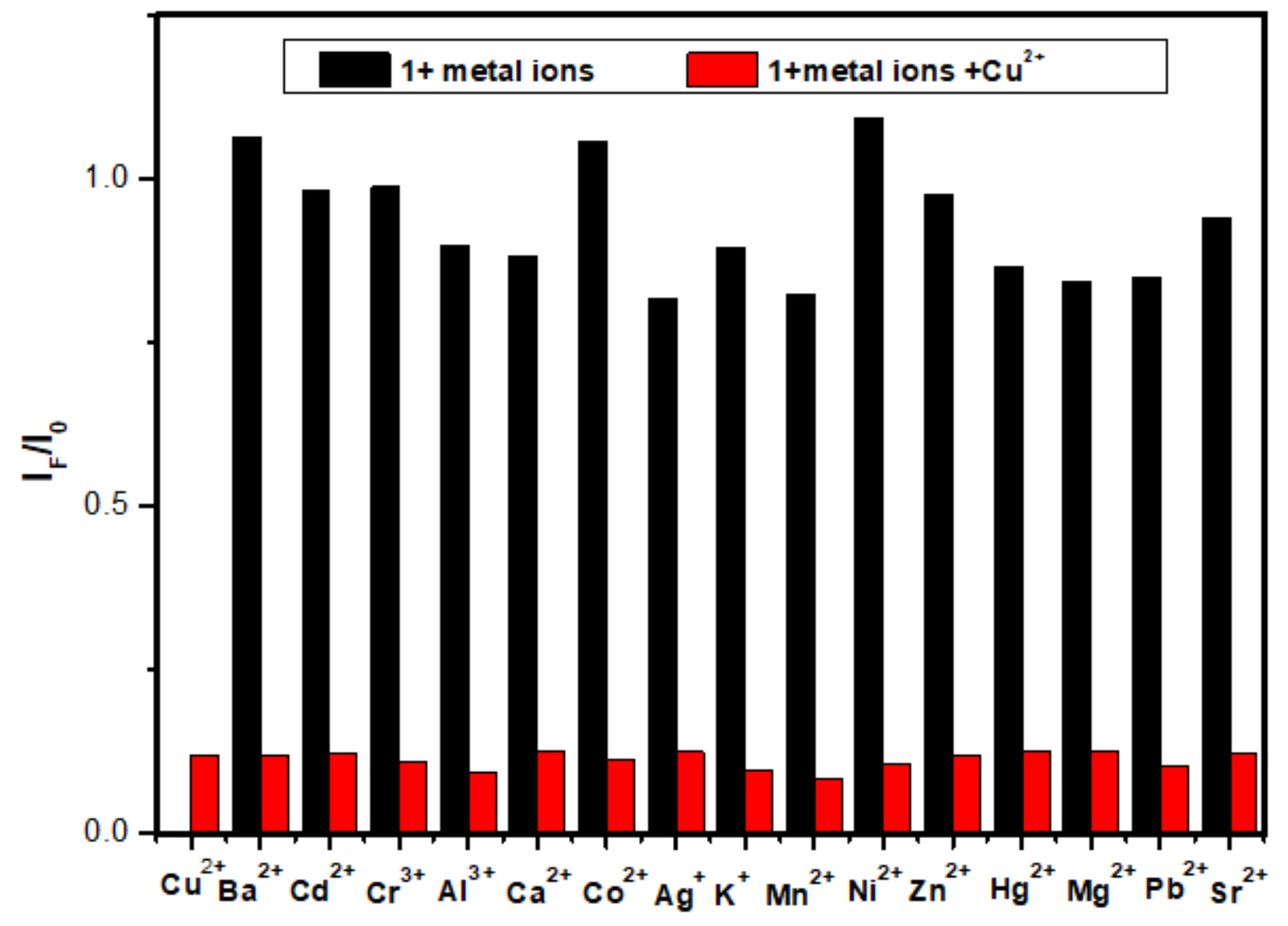

Figure 2

Fluorescence quenching degrees IF/I0 of $1(20 \mu \mathrm{M})$ valued at $376 \mathrm{~nm}$ in the presence of both Cu2 $+(5.0$ equiv) and competing metal ions (5.0 equiv). Black bars represent the addition of 5 equiv. of various metal ions to the solution of (S, $\beta-D)-1(20 \mu \mathrm{M}$ in $\mathrm{CH} 3 \mathrm{CN})$; Red bar represent the addition of the competing metal ion added with the existence of Cu2+. 10 states the fluorescence intensity of only (S, $\beta-D)-1$ and IF states the fluorescence intensity with the addition of the mixture of competitive metal ions and Cu2+.

(A)

(B)
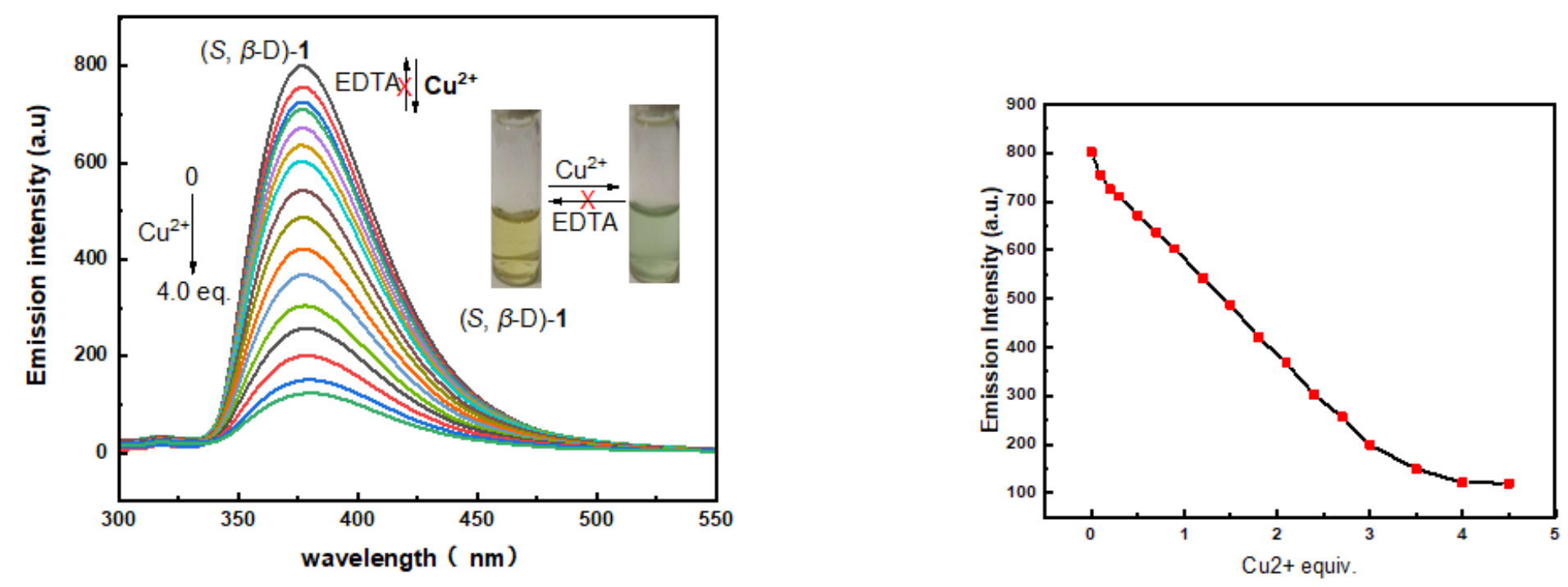
Figure 3

(A) Fluorescence responses of (S, $\beta-D)-1(2 \times 10-5 \mathrm{~mol} / \mathrm{L}$ in $\mathrm{CH} 3 \mathrm{CN}, \lambda$ ex $=287 \mathrm{~nm})$ in the presence of increasing amount $0-4$ equiv $\mathrm{Cu} 2+(0.01 \mathrm{M})$. (B) the change of fluorescence intensity at $376 \mathrm{~nm}$ upon various equiv. Cu2t.

(A)

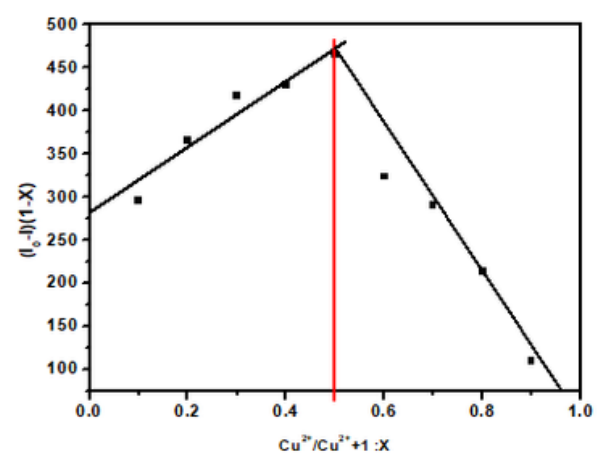

(B)

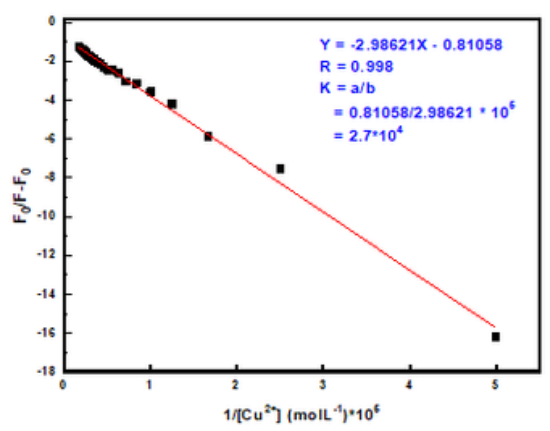

(C)

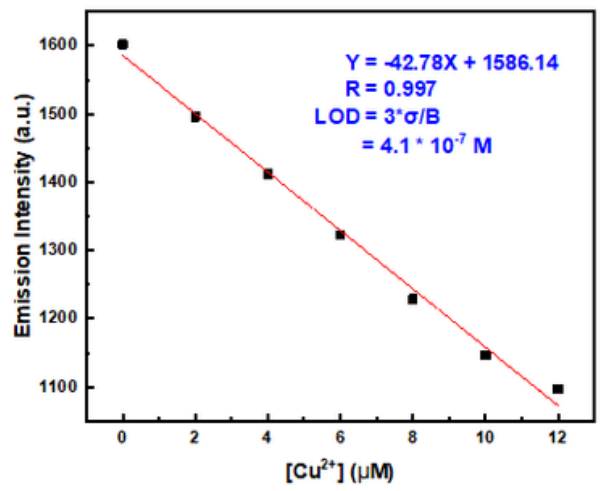

\section{Figure 4}

(A)The job plot of a 1:1 complex of (S, $\beta-D)-1$ with Cu2+. $X$ is the molar fraction of Cu2+. (B)HildebrandBenesi plot of $\mathrm{F} 0 /(\mathrm{F}-\mathrm{F} 0)$ versus $1 /[\mathrm{Cu} 2+]$ based on the $1: 1$ binding stoichiometry. The binding constant Ka was calculated to be $2.7 \times 104 \mathrm{~L} \cdot \mathrm{mol}-1$ (C) $\mathrm{LOD}=3.14 \times 10-7 \mathrm{~mol} \mathrm{L-1}$ 

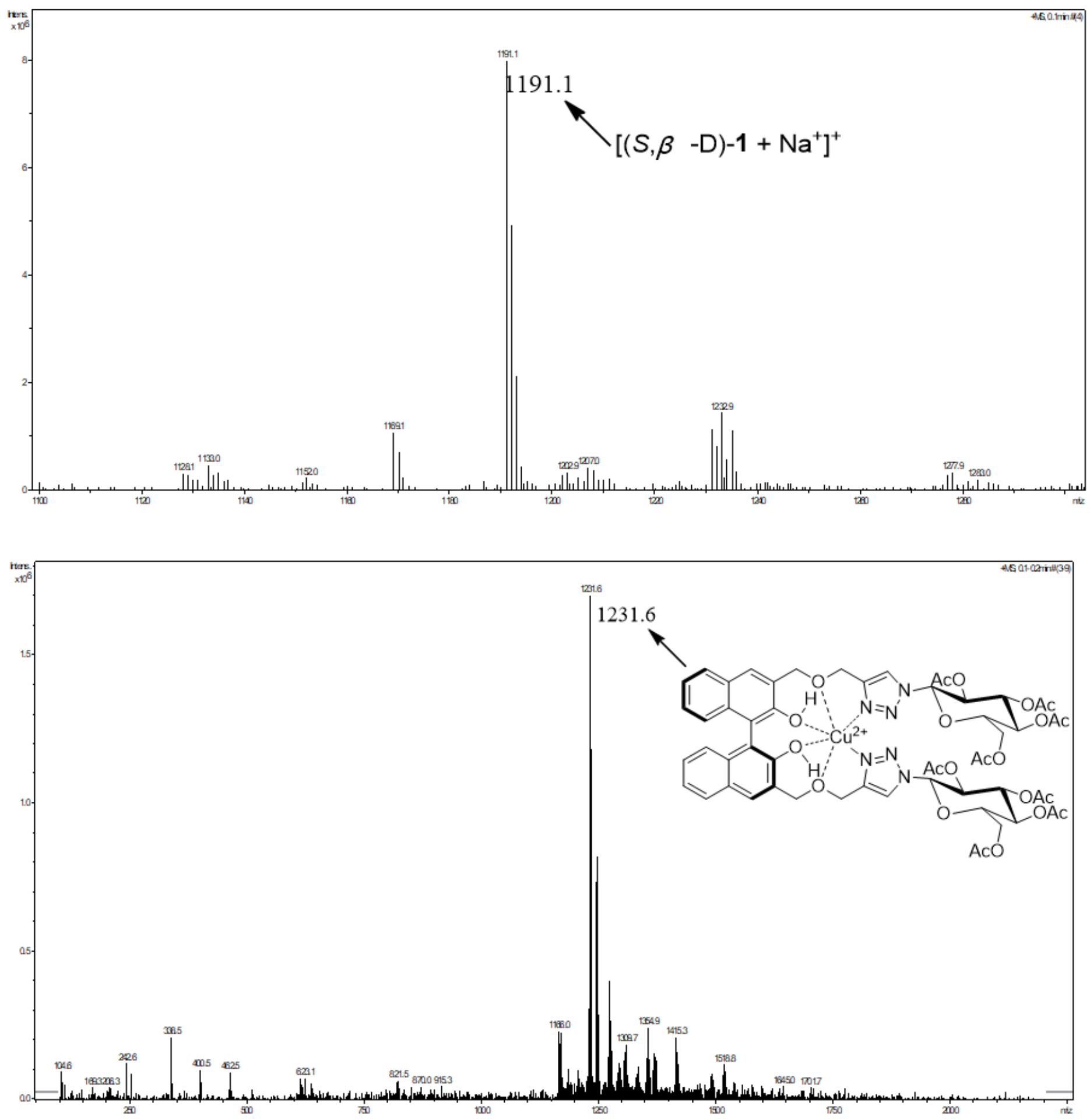

Figure 5

ESI-MS spectral changes in methanol. 


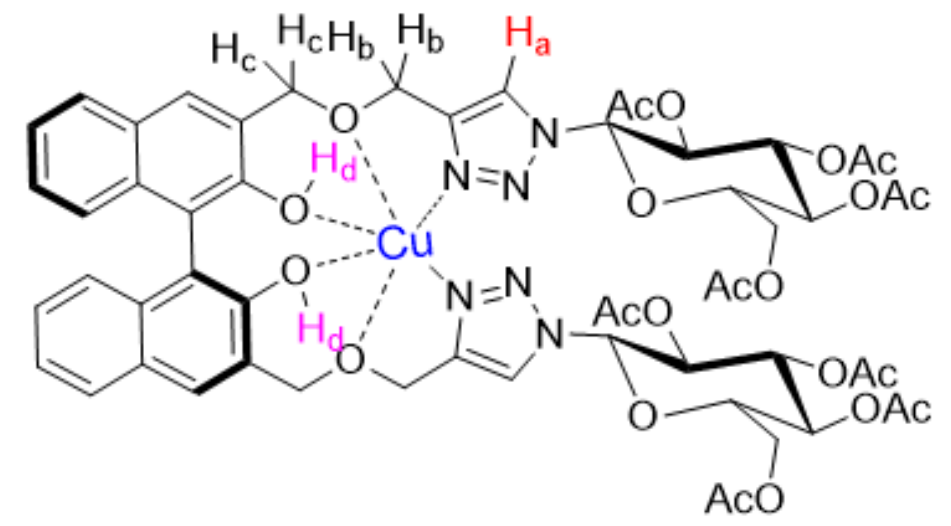

(d)
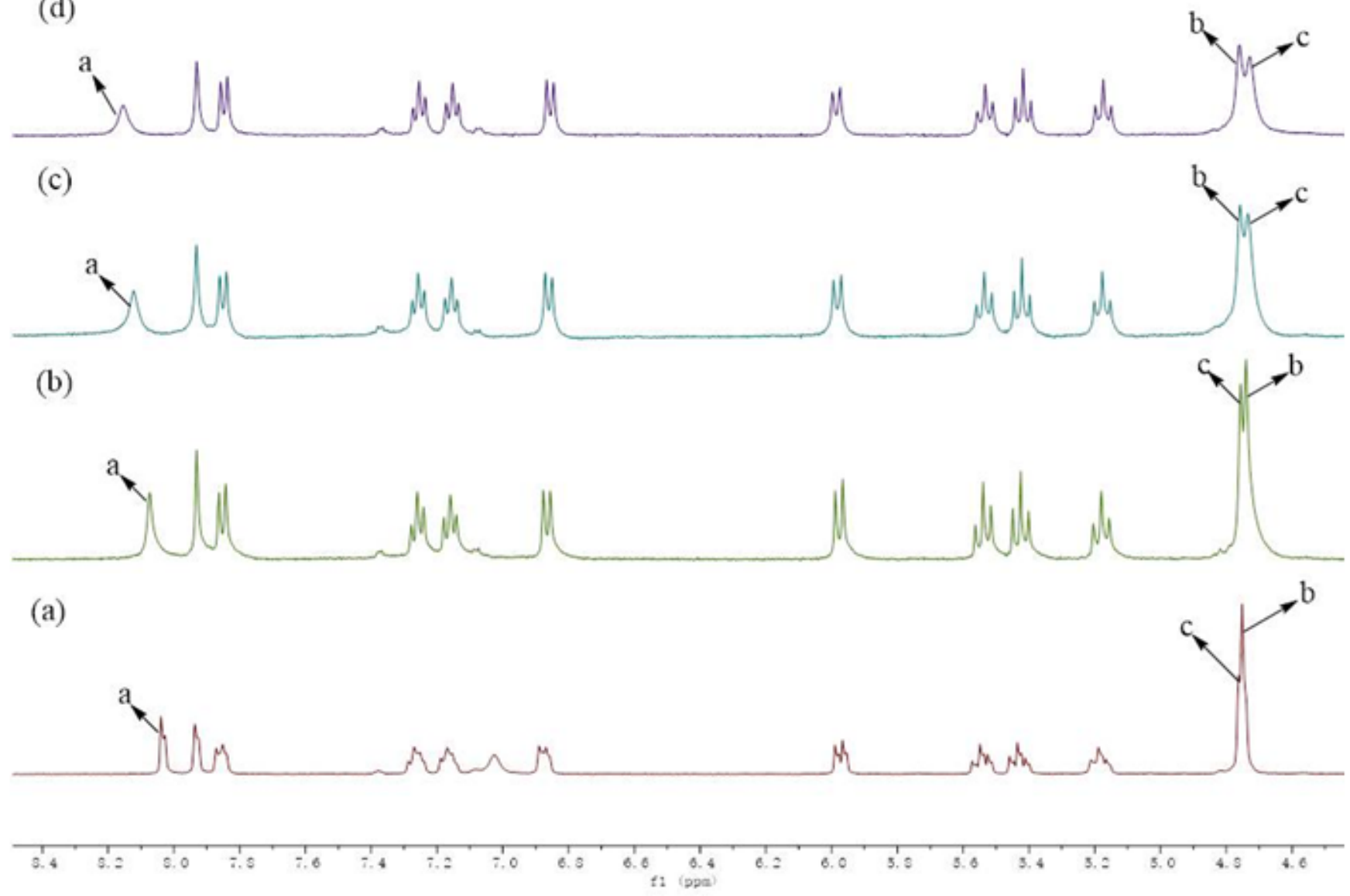

Figure 6

1HNMR spectra of (a) (S, $\beta$-D)-1; (b) addition of 0.3 equiv of $\mathrm{Cu} 2+$; (c) addition of 0.7 equiv of Cu2+ ; (d) addition of 1 equiv of $\mathrm{Cu} 2+$. 


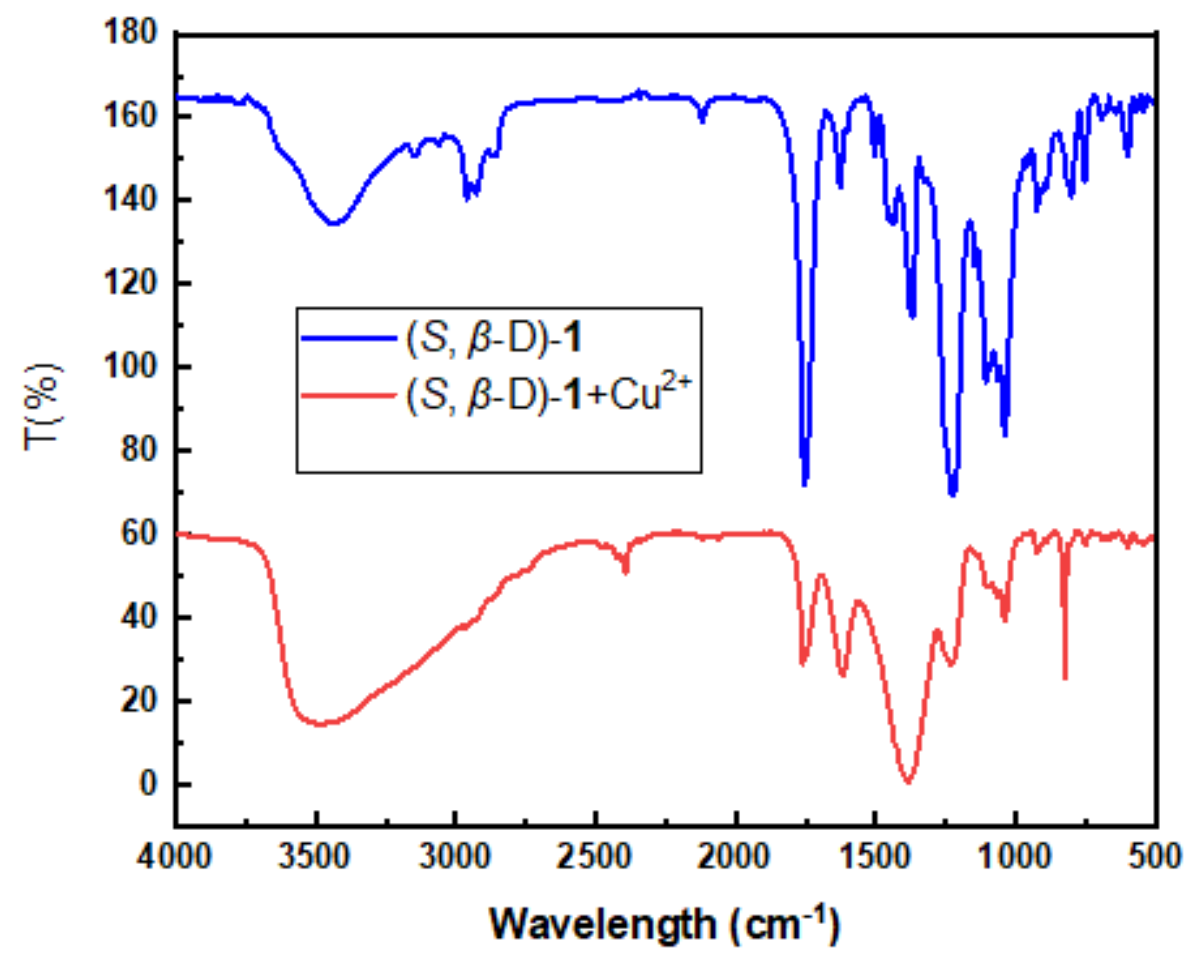

Figure 7

IR spectra of (a) (S, $\beta-D)-1$ and the 1:1 complex

\section{Supplementary Files}

This is a list of supplementary files associated with this preprint. Click to download.

- SCH2BINOLglucoseCusupplementarydata1.doc

- Scheme1.png

- Scheme2.png

- Graphicalabstract.png 